\title{
Correction to: Association Between Periodontal Diseases and Adverse Gestation Outcomes: a Review of the Current Literature
}

Davi da Silva Barbirato ${ }^{1} \cdot$ Monique Oliveira Rodrigues $^{2} \cdot$ Julianna Peres Alves $^{3} \cdot$ Heric Pinheiro de Castro $^{3}$. Mariana Fampa Fogacci ${ }^{4}$

Published online: 8 March 2019

(C) Springer Nature Switzerland AG 2019

\section{Correction to: Current Oral Health Reports https://doi.org/10.1007/s40496-019-0209-3}

The original version of this article unfortunately contained a mistake. The name of the 3rd author should be "Julianna Peres Alves."

The original version has been corrected.

Publisher's Note Springer Nature remains neutral with regard to jurisdictional claims in published maps and institutional affiliations.

The online version of the original article can be found at https://doi.org/ 10.1007/s40496-019-0209-3

Davi da Silva Barbirato

davibarbirato@gmail.com

Monique Oliveira Rodrigues

moniquerodrigues.mor@gmail.com

Julianna Peres Alves

juliannalves@gmail.com

Heric Pinheiro de Castro

heric.p10@hotmail.com

Mariana Fampa Fogacci

mari.fogacci@gmail.com
Post-Doctorate, School of Dentistry of Pernambuco, FOP, University of Pernambuco, UFPE PE, Brazil

2 Doctorate student, Federal University of Rio de Janeiro - UFRJ, Rio de Janeiro, RJ, Brazil

3 Graduate student, School of Dentistry, Faculdades Integradas Aparício Carvalho - FIMCA, Porto Velho, RO, Brazil

4 Professor, Department of Clinical and Preventive Dentistry, Federal University of Pernambuco, UFPE PE, Brazil 